\title{
A Distributed Theatre Experiment with Shakespeare
}

\author{
Doug Williams \& lan Kegel \\ BT \\ Adastral Park, \\ IPSWICH, Suffolk, UK \\ doug.williams@bt.com
}

\author{
Marian Ursu \\ University of York \\ Theatre, Film and Television \\ Baird Lane, York, UK \\ marian.ursu@york.ac.uk
}

\author{
Pablo Cesar \& Jack Jansen \\ $\mathrm{CWI}$ \\ Science Park 123, 1098 XG \\ Amsterdam P.O. Box 94079, \\ NL-1090 GB Amsterdam, NL \\ p.s.cesar@cwi.nl
}

\author{
Erik Geelhoed \\ Falmouth University \\ The Air Building, \\ Penryn, Cornwall, UK \\ erik.geelhoed@falmouth.ac.uk
}

\author{
Andras Horti \\ Joanneum Research \\ Steyrergasse 17 \\ A-8010 Graz Austria \\ andras.horti@joanneum.at
}

\author{
Michael Frantzis \\ Goldsmiths, \\ University of London \\ New Cross, London. \\ m.frantzis@gold.ac.uk
}

\author{
Bill Scott \\ Miracle Theatre Company \\ Redruth, UK \\ bill@miracletheatre.co.uk
}

\begin{abstract}
This paper reports on an experimental production of The Tempest that was developed in collaboration with Miracle Theatre Company realised as a distributed performance from two separate stages through a dynamically configured telepresence system. The production allowed an exploration of the way a range of technologies, including consumer grade broadband, cameras and projection technologies could affect the development and delivery of live theatre by regional touring company.

The architecture of the communication platform used to deliver the performance is introduced as are two novel software tools that are used to describe and control the way the play should be captured and represented. The experimental production was thoroughly evaluated and the feedback from audience and theatre professionals is presented in some detail.

A considered observation of the process and the way it differs from film, TV and theatre suggest that distributed theatre can be treated as a new genre of storytelling.
\end{abstract}

\section{Categories and Subject Descriptors}

Computer applications: ARTS AND HUMANITIES: Performing Arts

\section{General Terms: Design, Experimentation. Measurement}

Keywords: Distributed theatre; Broadband

\section{INTRODUCTION}

Shakespeare's plays have been performed on stage for over 400 years, but the way they are presented is often adapted to take advantage of new technologies. Innovations in staging, lighting, costumes, sound effects and props have all been used to re interpret the plays of the bard in ways that are meant to be attractive to audiences.

Permission to make digital or hard copies of all or part of this work for personal or classroom use is granted without fee provided that copies are not made or distributed for profit or commercial advantage and that copies bear this notice and the full citation on the first page. Copyrights for components of this work owned by others than the author(s) must be honoured. Abstracting with credit is permitted. To copy otherwise, or republish, to post on servers or to redistribute to lists, requires prior specific permission and/or a fee.

Request permissions from Permissions@acm.org

$M M^{\prime} 15$, October 26 - 30, 2015, Brisbane, Australia

Copyright is held by the owner/author(s). Publication rights licensed to ACM. ACM 978-1-4503-3459-4/15/10 .\$15.00

DOI: http://dx.doi.org/10.1145/2733373.2806272
This paper describes a detailed case study that explores how a range of technologies, including consumer grade broadband, cameras and projection technologies could affect the development and delivery of live theatre through an experimental production of The Tempest that was developed in collaboration with Miracle Theatre Company ${ }^{1}$. Miracle Theatre Company is a small, well established regional touring company that produces both familiar and new work across the South West of England. Since their goal is to bring theatre to people, they often perform in small outdoor locations using simple staging and lighting and sometimes in small community venues such as village halls. This approach enables them to reach remote venues but requires a form of theatre which places limited demands on staging, lighting, props and costume.

\subsection{Motivations}

The work described in this paper is motivated primarily by enquiry from commercial and artistic perspectives. The drive from these quarters creates a rare opportunity for scientific investigation with high ecological validity. To underscore and embed that opportunity the performance, carried out by a commercial theatre company with a reputation to maintain, took place in front of a paying audience. The complex blend of ambition, responsibility and jeopardy created a poignant mix of dread and excitement.

\subsection{Artistic Motivation}

Miracle Theatre Company's interest in this project was to explore the extent to which consumer grade fast broadband connections, cameras and screens can be used to help them to achieve their stated purpose i.e. to produce a rich mix of touring theatre, always with a unique comic style, joyful use of language and an immediate visual appeal. It embraces digital technology, nurtures new writers, performers, venues and promoters. Miracle works to build audiences by bringing 'big' shows to little venues. Miracle is committed to touring work which is innovative, but not intimidating, to communities in the far flung corners of the UK.'

The motivation for this work was thus to establish whether consumer grade fast broadband, cameras, and projection technologies could be used to deliver an engaging amusing performance to a paying audience whilst also exploring the extent to which it could extend audience reach, bring something new to

\footnotetext{
${ }^{1}$ www.miracletheatre.co.uk
} 
the theatre and even hint at new forms of creative artistic expression.

We also anticipated that consumer grade high speed broadband connections and the use of audio and video links would enable a different form of rehearsal practice, in which actors did not have to be co-located.

The play selected (The Tempest) was one the troupe had recently performed and that the Artistic Director felt lent itself to being performed in two locations; we could not afford to produce a brand new performance. The Tempest (1610-1611) is believed to be the last play that William Shakespeare wrote alone. It is set on a remote island where a magician named Prospero, the once Duke of Milan, lives with his daughter Miranda, having been exiled there by his younger brother Alonso. Prospero and Miranda share the island with Ariel, a nymph like spirit, and Caliban, a magical monster, both of whom are controlled by Prospero. Prospero, on sensing that his brother is sailing past the island, conjures a storm that shipwrecks Alonso, the King (with whom Alonso is travelling), and a number of their acolytes. The plot centres on Prospero who, using magic, exposes his brother's dishonest ascent to power and yet chooses to forgive him. It is filled with beautiful language and many comedic passages.

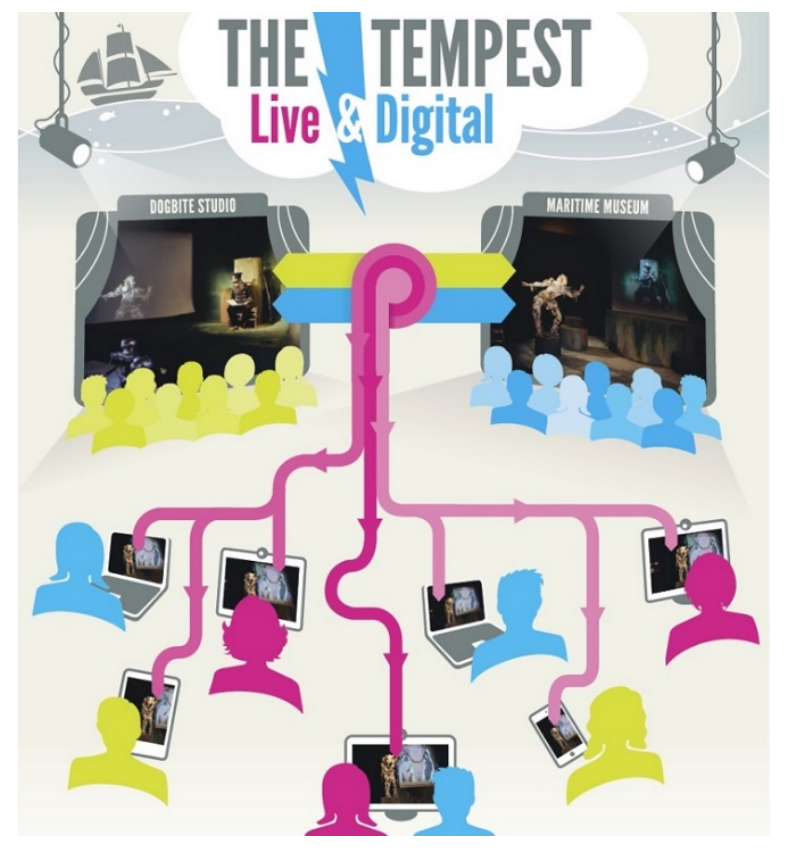

Figure 1 Schematic of the performance challenge, two performance spaces and an audience at home

In the distributed production, the actors are split between two locations but together deliver a single performance mediated by the cameras, consumer grade high speed broadband and projection technologies. This had an immediate appeal to the Artistic Director of Miracle Theatre Company as he envisaged being able to "give an extra dimension to the production of The Tempest by placing Prospero into some quite dramatic natural surrounding - like a cliff with the sea pounding behind him... and having the rest of the play taking place in a theatre with Prospero there on a screen and gently transporting the theatre to an environment that you wouldn't normally be able to do." This vision, whilst still valid, was moderated during the development stage.

Another motivation was to explore how the technology could allow the creative team to emphasise the nature and capabilities of the characters. Prospero, for example, can be seen as an eccentric, slightly reclusive but immensely powerful even God-like character. Ariel's magical qualities can likewise be enhanced using affordances of the distributed performance and the technology.

\subsection{Technical Motivation}

We selected Cornwall in the UK as the location of the performances because Cornwall was enjoying an accelerated deployment of fast broadband connection through the Superfast Cornwall Project ${ }^{2}$. This project was exploring the impact of the deployment in terms of the way it affected education, industry, tourism, culture and employment. In this work we explore how consumer grade fast broadband connections could have an impact on live performance.

There were two main technical objectives; the first was to establish whether it was possible to stream live theatre over consumer grade fast broadband connections; the second was to explore the capabilities of a system based on controllable cameras that semiautomatically develop simultaneous live streams, based on a scripted set of camera selections, for three different audiences (two theatres and the Internet audience).

Filming and broadcasting theatre began in the 1930s [1]. Live streaming theatre to cinemas, using satellite technology, is a practice used today by large theatre companies like the Metropolitan Opera and NT Live. It is reported to strengthen their brand and enhances all forms theatre attendance [2]. However it is expensive and only really viable for the larger, more successful, theatre companies. Distributed theatre experiments have shown what is possible using advanced high speed networks [3]. This exploration sought to explore what could be achieved using consumer grade fast broadband connections [4]. Through separating the performance of an established touring play between two locations, and mediating that performance using technology it is clear that the performances have to be adapted: the actors can no longer deliver the performance they use for the single stage performance. This production explores how this can be done with unmanned relatively low cost cameras and explores the degree to which the semi-automated cameras can enhance the storytelling for both the audiences in the performance venues and the online audience.

\subsection{Scientific motivation}

Part of the scientific motivation of this work was inherited from the Vconect project that developed the technology. The Vconect project $^{3}$, sought to improve ad hoc communication between groups and the video communication platform developed by the Vconect project [5] was used in this distributed theatrical performance.

The project postulated that changing the way audio and video were captured, transmitted and presented could positively affect group communication by improving the quality of mediated communication and by enabling more complex communication setups to be supported. To test this, its sophisticated video communication platform was deployed in two diverse setups. One in the context of an online social network [6] and this trial in distributed theatre. The use of the technology in these settings

\footnotetext{
${ }^{2}$ Superfast Cornwall is a programme funded by the EU, BT and Cornwall Council, and managed by Cornwall Development Company, a local authority company controlled by Cornwall Council.

3 Vconect received funding from the European Community's Seventh Framework Programme (FP7/2007-2013) under grant agreement no. ICT-2011-287760
} 
allowed us to explore, in an holistic experiential way, whether this postulation was valid.

The distributed nature of this performance also allowed us to explore, in an ecologically valid context, the differences in the responses to live theatre of remote and local audiences. This is an important component of developing satisfying and sustainable theatrical performance that can be enjoyed at a distance.

\subsection{Experimental Approach}

The approach adopted in this work is represented in Figure 1; it depicts two performance spaces (the Dogbite Studio and the Maritime Museum) each with a local audience, plus an audience watching live video streamed over the Internet.

The Dogbite Studio performance space was host to Prospero and his assistant Ariel. The second location, the Maritime Museum, played host to the remainder of the cast. Ariel, who is sometimes invisible can easily move between the two locations. In this production the role of Ariel was performed by two actors, one in each location.

The Dogbite Studio consisted of a simple stage, two screens and two cameras. Prospero and Ariel could be seen on the stage and the action taking place in the Maritime Museum could be observed on one screen. On occasions Prospero found himself in conversation, through the screen, with Ariel in the Maritime Museum. At other times he merely observed the action. The other screen was used to overlay recorded video onto the physical performance space.

In the Maritime Museum the actors had a stage, a screen and four cameras. The screen here showed Prospero in conversation with Ariel but also illustrated portions of the story that took place in Prospero's location.

In order to evaluate this case study we provided questionnaires for the audiences and also took the time to interview key participants from the theatre company to better understand the experience from their perspective. We also encouraged all of the technical team to be aware of, and to reflect upon, the things that went well, things that surprised them and things that did not work so well. All these sources of information were collated and provide a rich insight into the experiment.

\section{RELATED WORK}

Performance artists have creatively made use of physical and, more recently, digital illusionary tools: "there is nothing in cyberspace and the screened technologies of the virtual that has not been already performed on the stage. The theatre has always been virtual, a space of illusory immediacy. " [7]. It is not our intention to survey all the various efforts from artists to exploit technology to enhance performances, since [8] and [9] already provide comprehensive overviews. Nevertheless, there are a number of recent pieces that showcase current directions and challenges. "Skype Duet" [10] is a distributed live performance between New York and Berlin. Organisations like "Dimanche Rouge" promote experimental performances that have included actors and dancers accompanied by pre-recorded video and other multimedia work that has been streamed live between Paris and New York providing opportunities for distributed audiences to interact, give feedback and even co-create [11]. "Discovering Pasolini: Notes on an unborn movie" [12] is a project that was developed and performed with telepresence technology at Teatro La Pergola Firenze. In "Graphic Ships" [13] musicians and a dancer are distributed across locations. Visuals are created based on the movements of the dancer, captured by motion sensing, and create a graphic score from which the live musicians improvise the musical accompaniment. The audience sees the live movement of the local dancer, the visualization her movement creates and simultaneous projections of the multi-sited musicians themselves. Finally, "The Return" [14] shows one performance, which happened simultaneously (with audience) in two spaces, and with people that followed the live streaming from different parts of the world.

All these pieces connect two or more locations with the aim of creating a single performance. With the emergence of pervasive low cost videoconferencing systems, such as Skype, perspectives in the mediated performance space have been broadened. With the technology becoming so much more accessible there has been an increase in mediated performances. Cinzia Cremona [15] puts it succinctly: "Skype communication and video-performance have been converging into a set of art practices that adopts the screen as a relational device." Our work is significantly different. From an artistic perspective the goal was not so much on experimental theatre, but on understanding how a local theatre company could appropriate novel technologies for the transformation of a singlestage play into a distributed performance. From a technical perspective, we took the conscious decision of not using commercial systems like Polycom and Skype (except the out of band channels used by the production team, where Google+ Hangouts was used). Instead we built our own infrastructure over which we had full control. The infrastructure was somewhat based on the one we have previously used for enabling remote gaming between homes [16] so it provided a low delay communication and rich composition capabilities. Unlike other research approaches that take advantage of very fast networks between universities [3] and simulations [17], this experiment uses consumer grade fast broadband products. At the aesthetics level, our system provides rich composition capabilities, beyond existing videoconferencing systems, for combining a variety of video inputs (including prerecorded media) for a variety of outputs: the other theatre, online audiences, etc.

Companies such as The National Theatre live stream one-stage productions to cinemas [18]. As a one-way communication system, they miss information about the reaction of the audience [19], [20] and do not provide means for the audience to interact, except out of band using system like the social network Twitter. Previous works have considered interactivity based on mobile phone usage [21] or messages [22]. In our case, we provide audience awareness between the locations based on the audiovisual communication. One key innovation, which brings the overall budget for a production down, when compared to services such as NTLive, is our innovative mechanism for scripted automatic control of the cameras that capture the play and the audience.

\section{TECHNOLOGY PLATFORM}

The video communication platform developed by the Vconect project [5] to address the challenge of supporting complex use cases for multimedia communication between ad hoc groups incorporates three innovations over state-of-the-art video communication systems:

- The use of communication modelling and automatic reasoning, which we call orchestration, to determine how best to employ the capabilities of a given system (cameras, microphones and displays) to meet the communication needs of each participant.

- Multimedia composition functions which enable real-time streams and pre-recorded content to be synchronised and rendered just-in-time at multiple clients, under the control of a central orchestration system.

- A 'service-aware' network in which the selection and routing of media streams is dynamically adapted in order to balance 
quality of experience against the cost and capabilities of the resources available.

The Vconect platform was deployed and extended for our trial of The Tempest, using the architecture shown in Figure 2. The figure is divided into three layers which represent groups of physical locations: the two performance venues (top), private homes (bottom) and the Vconect platform, hosted in London (middle). In the platform architecture, audio and video are carried in separate streams and are processed independently, while the system as a whole is tuned to ensure correct synchronisation. Audio processing components such as the Audio Communication Engine (ACE) and the Multi-point Control Unit (ACE-MCU) are shown in purple. Video processing components such as: the Studio Client; the Video Router and the Video Bridge are shown in blue. Components associated with orchestration and control of the service-aware network such as: Sync Control, Performance Orchestration Engine and Optimiser are shown in green. The platform uses a message broker, based on Apache ActiveMQ, for mediating control messages between all components. Control messages include communication cues, commands, signalling, synchronisation and network monitoring data. The architecture achieves the dual goals of linking two theatre environments and presenting a coherent experience to remote audiences joining over broadband. A Web Streamer component relays audio and video streams from the platform to an external web broadcasting service (not shown) for onward delivery to viewers in their homes.

\subsection{Audiovisual Capture and Presentation}

A key challenge for audio in a distributed theatre setting is forestalling feedback and echo effects from delayed playout at each location. We addressed this by using miniature directional bodyworn microphones which were relatively immune to audio from the PA loudspeakers. The audio mix in each location (including additional pre-recorded effects and music) was captured and transmitted by the Audio Communication Engine (ACE), a Voiceover-IP (VoIP) client allowing multichannel audio and echo control with low delay $(<50 \mathrm{~ms}$ end-to-end) and full audio bandwidth $(24 \mathrm{kHz})$. The audio system design was significantly more complex than a single theatre environment, but only standard equipment was required in addition to the ACEs.

Professional video conferencing cameras were used due to their high quality optics, good low-light performance and Pan/Tilt/Zoom heads which could be remotely controlled. HD video projectors displayed images on fabric screens in each location; the screens were about $3 \mathrm{~m}$ in diagonal. Video capture and rendering was managed by the Vconect Studio Client, a set of applications that together implement a highly customisable platform for video conferencing. Based on the Ambulant multimedia document player, the Studio Client used SMIL [23] documents to define and render composition layouts for live streams and pre-recorded video, plus transitions and animations. The SMIL language can easily capture composition requirements, both spatial composition (where things will appear on screen) and temporal composition (when they will appear). The SMIL document structure was further extended to store details about available camera positions and video encoder settings, as well as the location and relative position of the available projector screens. Video captured by the cameras was H.264encoded using HD (720p) resolution, at a frame rate of $25 \mathrm{fps}$ and a target bandwidth of $2 \mathrm{Mbits} / \mathrm{s}$. During the performance, each Studio Client controlled the PTZ head of each of its connected cameras in order to reframe shots when instructed by the Performance Orchestration Engine.

\subsection{Audiovisual Transmission and Routing}

The Vconect platform provided a hybrid transmission and routing architecture to suit the needs of a distributed theatre performance. For audio, the ACE-MCU is a full-bandwidth audio bridge which provides an appropriate mix of incoming streams for each connected client, thus allowing the Web Streamer to transmit audio from both sets of actors to home viewers while at the same time connecting audio between each performance location.

Video streams were connected between each performance location using a Video Router, a highly-efficient UDP packet switch capable of handling multiple incoming video streams and switching or duplicating them to various outputs at any time in response to instructions from the Optimiser. The platform also included a Video Bridge, which performed a similar function to traditional bridges used in video conferencing today. The Video Bridge was used to render a single composite version of the performance at both locations at any one moment. This was forwarded via the Video Router to the Web Streamer for onward delivery to the home viewers. The combination of Video Router and Video Bridge offers further benefits which were not fully explored during The Tempest trial, including the ability to render a preview of all available video sources for presentation on preview monitors for members of the crew.

In the Vconect platform, the Optimiser component is responsible for monitoring low-level information about network performance and working in conjunction with the Orchestration Engine to dynamically adapt the configuration of video streams to costeffectively deliver the best Quality of Experience. However, for The Tempest trial, the capabilities of the consumer grade fast broadband network connections in each performance location were known well in advance, and exclusive access was negotiated for the duration of the performances. This meant that the Studio Clients could be preconfigured to the optimum settings and dynamic adaptation within this part of the system was unnecessary. The main role of the Optimiser was therefore to provide reliable setup of connections between the two Studio Clients, the Video Router, the Video Bridge and the Web Streamer, and to enable monitoring and debugging at runtime.

\subsection{Orchestration and Composition}

Theatre is scripted and this changes significantly the way we think about how to choose which camera views to select for transmission. In live systems used to represent video communications, complex algorithms can be developed that dynamically determine how best to represent the conversation [24]. But in theatre the director can select, in advance, the best camera shots. This is similar to film (the action is scripted) but also has similarities to live television where there is no "take 2"; as such the production team have to develop a filmic language based on a limited number of possible camera views, selected live during the performance.

The precise timings of events in theatre will change from night to night even if the sequence should not. For this reason a system had to be developed that would control the cameras, moving them in sync with the theatrical script so that they framed the action in the way that the director viewed was best for the audience. 


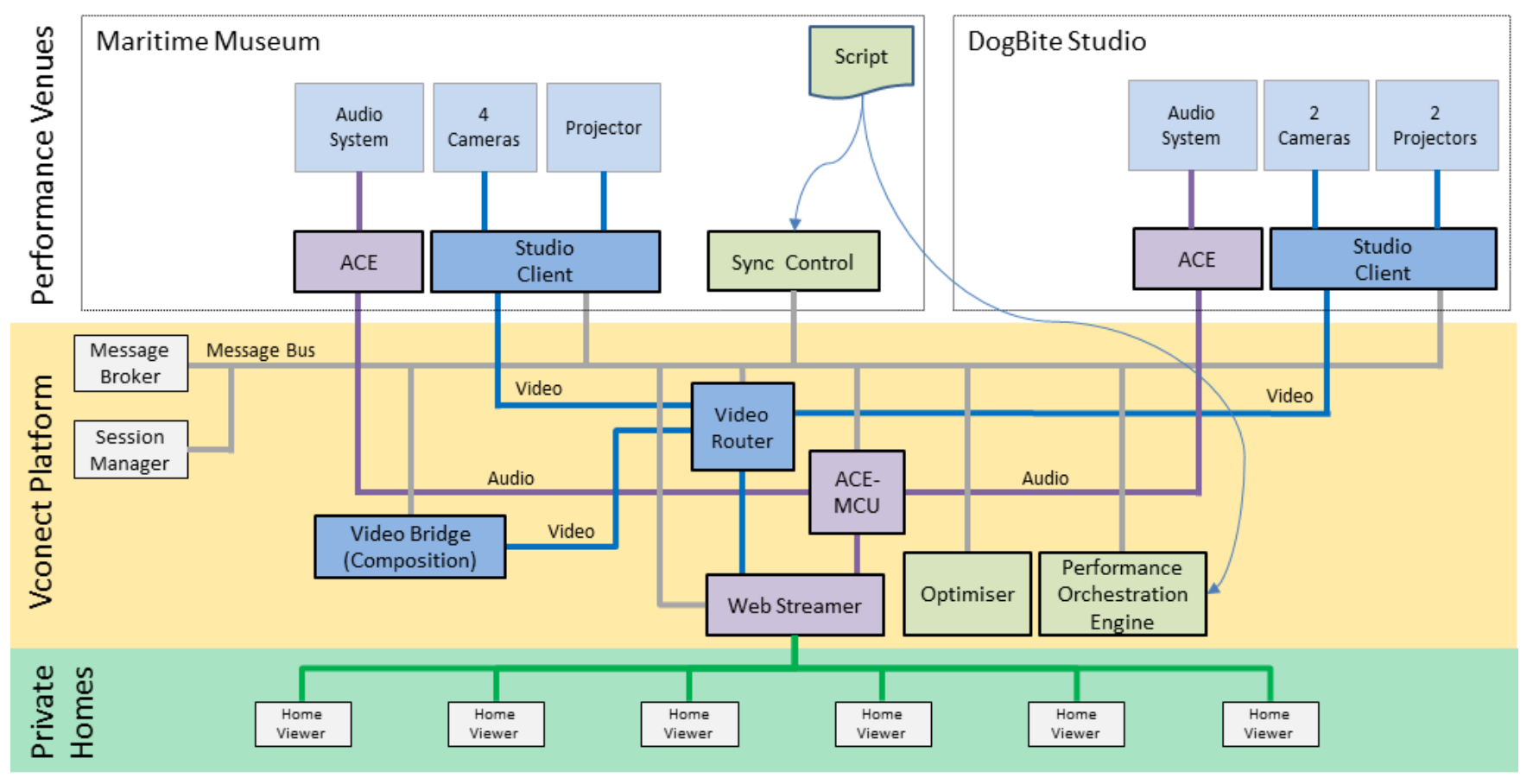

Figure 2 The Vconect platform as implemented for The Tempest trial

The requirement was for tools which can take a theatrical script and link it, via a set of cues, to editable audiovisual representation instructions. These instructions exist as a script which can be executed by the Performance Orchestration Engine. The components need to achieve this, some of which are in Figure 2, include:

1. A set of PTZ (Pan/Tilt/Zoom) positions, camera configurations which have been predetermined to capture the creative intention of the director at certain points in time.

2. A set of Composition Layouts, each determining where live streams are displayed, possibly augmented with pre-recorded media and visual effects.

3. A Script Editor. A software tool which was used to create a description of the way the play should be represented on the screens in the audience locations. We call this description the "representation script". Representation scripts are both readable/editable by operators, and can also be executed automatically by the Sync Control component.

4. A Sync Control component. This component displays, in a userfriendly form, the representation script and allows an operator to synchronize the devices in each theatre with the stage performance.

5. A Visual Composition Engine per theatre and one for the home audience. These engines execute the PTZ position and composition layout commands, under control of the Sync Control component. Each Studio Client contains a Visual Composition Engine, as well as the Video Bridge.

A significant aspect of the system is the user interface for the Script Editor. The model chosen to achieve this also borrowed from existing methods in cinema, specifically for the user interface for a script editor. The standard interface, which appears in many modern non-linear editing (NLE) systems of a timeline with parallel tracks on which material can be placed, served as a useful model. However the tracks in the Vconect system differ from those in an NLE in two important respects, which make it a much richer model. Firstly, the timeline is not a sequence in minutes and seconds, but a sequence of cues which correspond to moments on a theatrical script. Each cue can trigger multiple actions. Secondly, the parallel tracks on the timeline do not represent media items but rather sets of instructions to different components - screens, layouts and cameras.

It is worth noting that, besides meeting the technical requirements for building the creative artefact via the relationship between creative professional and the Performance Orchestration Engine, the Vconect architecture supports some important functionalities required to help the director and actors achieve their goals in the context of the final mediated environment. For example, additional video feeds can be required for monitoring the performance, or the audio channels can support communication between director and performers in a number of different locations. These were not part of the initial system, but emerged as requirements during the trial.

\subsubsection{PTZ positions and Composition Layouts}

Early in the production, placeholder decisions were made about how things would appear on the on-stage screens and for the home audience. In each location (where for the purpose of composition we consider the feed to the home viewers as one location) there can be a combination of pre-recorded media and live feeds from specific camera angles. To these media items and live feeds visual effects can be applied, such as crossfading, semi-transparent overlays, etc.

These layouts are then encoded into SMIL fragments. Each SMIL fragment may contain any number of pre-recorded media items such as video clips or images, to be played out at a certain time after the activation of the fragment, and any number of placeholders for live streams. Each layout is named to reflect the intent of the layout and to make their role clear when they appear in the Script Editor. Names such as "FullScreen" and "Prerecorded clip with pillar fading into live feed" are examples that worked well. 

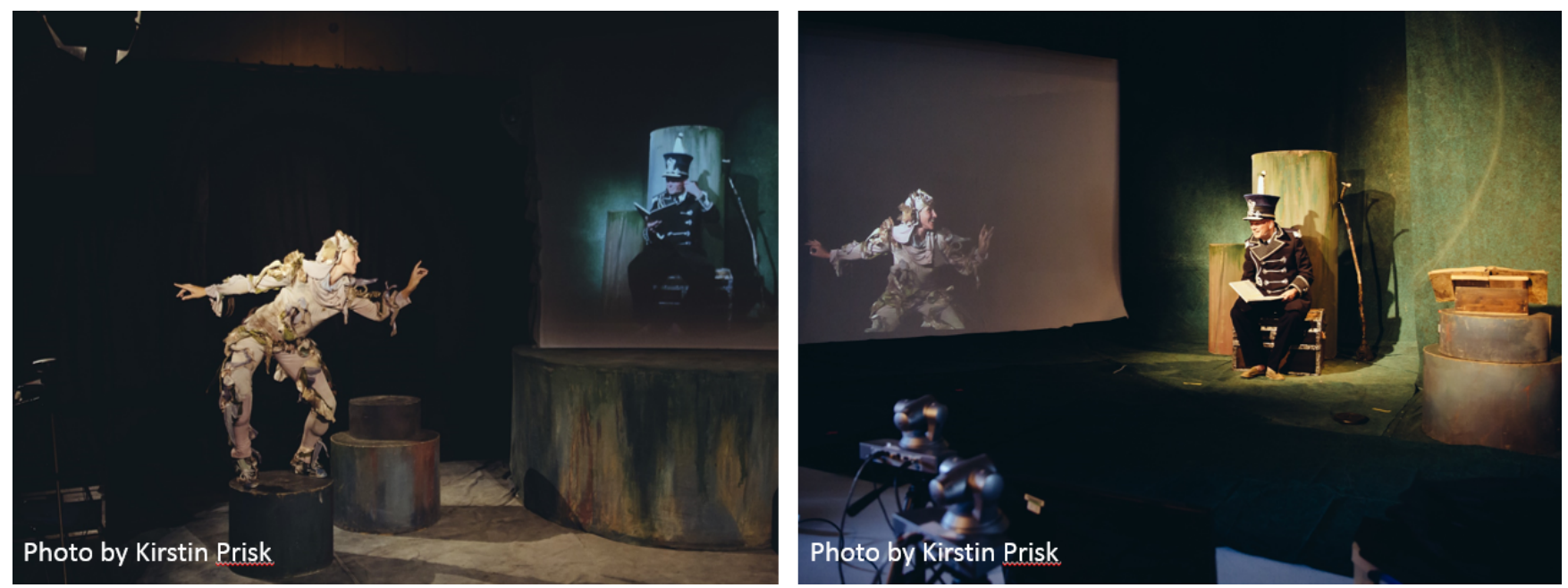

Figure 3 Illustration of the performance in the two venues. The two images shows the same moment fom the two venues. The left image shows the view in the Maritime Museum (The Island) whilst the right view shows the view in Dogbite Studio (The Lair). They feature Catherine Lake (as Ariel) and Angus Brown as Prospero

\subsubsection{Script Editor}

The Script Editor used the notion of scenes and cues to locate the script representation within the play. Each scene may be punctuated by cues which were labelled uniquely. For each cue sufficient information was provided to unambiguously define what each camera is capturing and what is being shown on the screens in each of the performance locations. These include:

- Narrative - a human description of the scene's events (e.g. "Miranda watching sea")

- A description, for each Camera, of what is being captured (for example "Island-Camera3_Wide"). A descriptive term, such as "Wide", corresponds to a specific triple of Pan, Tilt and Zoom settings for that camera. Any number of descriptive names and triples can be described for each camera; these may be general, such as "Wide", or related to a specific scene such as "CloseUp (Ariel double and Prospero with puppet)".

- A description, for each of the audience locations (Dogbite, Maritime museum and the Home viewers), of what is being shown. The screen content is described using a layout description and the identifiers of the cameras that are displayed within this layout.

For example, at a specific cue, the script editor will indicate that Island-Camera3 is being shown full screen in DogBite studio

\subsubsection{Sync Control}

The Sync Control component allowed an operator to synchronise the execution of the representation script with the pace of the performance. The design focus was simplicity, usability and ways to recover from a technical breakdown during a live performance. The user interface included one area that showed the representation script in natural language and one area that showed the controlling view i.e. an area that showed information about the previous, current and next performance sections. This controlling area included identifiers such as the cue name and the narrative text together with all the camera and screen commands that correspond to the cue. This technical description combined with the information from the natural language script helped the operator to ensure that the chosen cue entry corresponded to the action on the stage and that the system components were all running correctly. A "Send Cue" button sends the data of the cue shown in the middle horizontal section and positions the user interface to the next cue.

The interface also included a "Go to Cue" function that allowed the operator to jump to a specific cue - an essential feature in the event that, due to human or technical error, the representation script became desynchronised with the performance. In case of emergency there were two "panic" configurations which shift the representation to a wide shot.

\subsubsection{Visual Composition Engine}

Each Visual Composition Engine (whether embedded within the Studio Clients or the Video Bridge) is responsible for rendering live streams and pre-recorded media to one or more screens or encoded output streams. It receives three types of instructions from the Sync Control component:

- switch to a new layout,

- switch a particular live stream within the current layout to another camera

- position a specific camera to another PTZ angle.

The Visual Composition Engine is responsible for maintaining accurate synchronization of media items, and for displaying all media items at the right place on the screens, with the right visual effects, and at the right time. This separation of responsibilities between the composition engine and the Sync Control has the effect that Sync Control does not have hard real-time requirements because these are handled by the Visual Composition Engine. And the composition engine is not responsible for story line sequencing because this is handled by Sync Control.

\section{OUTCOMES}

\subsection{The Performance}

The Tempest, was performed on Tuesday September $8^{\text {th }} 2014$ and appeared as illustrated in Figure 3. The total audience was about 60; with about 40 being seated at the 'Island' location (the Maritime Museum), and about 20 in 'The Lair' (Dog Bite studio) and further 30 or so watching on line. A handful watched from both performance locations - swapping locations at the interval

Throughout the development of this play the theatre company had communicated with its audience with a tag line "expect the 
unexpected" and expectations were again set when the Artistic Director, during his introduction to the performance, wryly commented that, "...given the large numbers of computers involved I shall be bold. I will not say that something may go wrong I shall say something will go wrong."

Remarkably, given the known jeopardy, this daring distributed performance of The Tempest to a paying audience worked. The play suffered only one short stoppage and this was because a microphone was not switched on; it did not materially affect people's enjoyment of the play and was not commented on in the feedback sheets. As the General Manager of Miracle Theatre Company commented: "I could not believe that when we came to do the actual thing it literally worked the whole time when it hadn't gone for more than about 15 minutes in all the run ups."

Results are presented from three main sources. The first source is system performance measurements; the second source is the responses to the audience feedback questionnaires, these are mixture of quantifiable subjective assessment and qualitative subjective assessments. The third source is the reflections of those involved in the production. They include extensive interviews with members of the Miracle Theatre Company which took place a few months after the performance.

\subsection{System Performance Metrics}

Bandwidth measurements of $76 \mathrm{Mbits} / \mathrm{s}$ downstream and $18 \mathrm{Mbits} / \mathrm{s}$ upstream were made in each of the two venues using a standard web-based speed test tool ${ }^{4}$. Given that we chose an encode rate of $2 \mathrm{Mbits} / \mathrm{s}$ per stream during the rehearsals, this bandwidth was nominally enough to support all the traffic we anticipated generating.

Analysis of the video showed that the action as displayed in the remote location lagged the action in the local location by $320 \mathrm{~ms}$. Transmission delays were dominated by delays in the capture, encoding and packetisation; transit over the broadband link (to London and back, about $500 \mathrm{~km}$ ) amounts to only $3 \mathrm{~ms}$.

Delay in the audio transmission can be made much shorter than the delays in the video transmission. In this set up we had the option of adding delay into the audio chain to achieve good synchronization between the audio and the video.

\subsection{Audience Response Metrics}

Audience members were invited to indicate their responses to a range of questions by making a mark on a scale that ranged between 'Not at all' and 'Very' see Figure 4. The marks were recorded as normalized values between 0 and 100 based on the location of the mark respondents made on the scale.

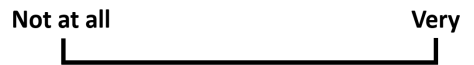

Figure 4 Response scale used to collect audience responses

The questionnaire offered respondents an opportunity to add comments. We received 47 questionnaire responses. The questions included:

1. Overall: How much did you enjoy the performance?

2. How immersed were you in the action that took place in the room where you were?

\footnotetext{
${ }^{4}$ The network testing tool we used was www.speedtest.net, other tools that work in a similar way are also available. We do not think the selection of tool is critical.
}

3. How immersed were you in the action that took place in the remote location?

4. How close did you feel to the actors in the room where you were?

5. How close did you feel to the actors in the remote location?

6. How close did you feel to the audience in the room where you were?

7. How close did you feel to the audience in the remote location?

8. How well did the action flow between the two locations?

9. How well could you see the action in the remote location?

10. How well could you hear the actors in the remote location?

11. How loud did you clap at the end of the performance?

In Figure 5 these results are reported with a colour code that illustrates whether the questions related to the performance overall, to the co-located part of the experience (i.e. to do with the performance in the venue in which the respondent watched the play) or to do with the performance from the remote venue.

\subsection{Interviews with Experts}

Video recordings of three interviews with key members of Miracle Theatre Company were made. These included the Artistic Director, the General Manager and an actor. These interviews provided about 2 hours of loosely structured conversation exploring their reflections on the experience. Further telephone interviews were carried with the operator of the sync control UI and with other members of the technical team some of whom also offered written reflections on the performance and of the experiment.

\section{RESULTS AND DISCUSSION}

\subsection{System Performance Metrics}

Whilst the speedtest.net results suggested we had plenty of bandwidth, we found we could not transmit traffic without modifications to the router settings. Firstly, because the broadband router had a short keep-alive timeout which was conflicting with the VClient's NAT traversal implementation, we set up a static port mapping for UDP video streams to the Studio VClient internal IP address. Secondly after observing poor long term stability we identified that the broadband router performed traffic shaping on long lived connections in order to prioritise more normal tasks like file transfer. This feature had to be turned off.

\subsection{Audience Response}

In Figure 5, the average score for each of the questions are arranged in rank order (error bars are the 95\% confidence interval). It is clear that the scores receiving the lowest scores related to the performance in the remote location. Question 7 "How close did you feel to the audience in the remote location?" received the lowest score (about 16). This is not surprising, no systems were in place to attempt to build any awareness between the audiences in the two locations. This response therefore can be taken as a baseline, a function of the scoring method and factors that have nothing to do with the technology set up. The other scores all relate to questions where the system was designed to address the issue in hand. These scores ranged from 55 to 80 , on a scale of 100 , which we interpret as generally positive. Gratifyingly one of the highest scoring responses was question 11 "How loud did you clap at the end of the performance?"

These responses are subjective and whilst quantitative they do not provide much insight into why our paying audience made these assessments. We gained more insights about what the 
respondents were thinking through the comments. Through a detailed treatment of the questionnaire results, that included covariance analysis and a multi-dimensional scaling analysis (to be reported elsewhere) it emerged that the variable which covaried most strongly with other variables was question 2 - the one about remote immersion.

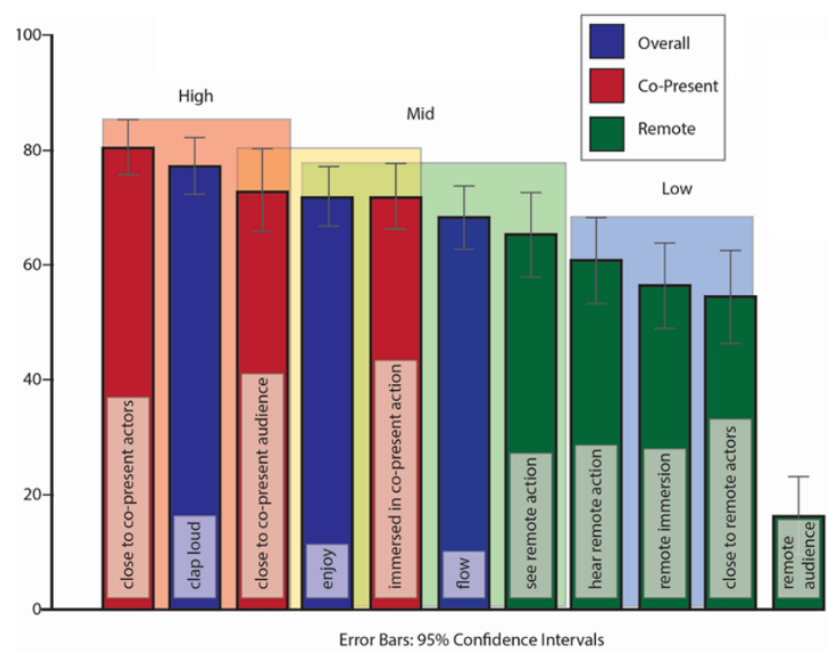

Figure 5 Questionnaire responses, colour-coded to highlight responses related to the performance overall, to the co-located performance only and to the remote performance only.

To help highlight the difference in commentaries provided by those who reported feeling immersed and those who were not immersed we ordered the responses with respect to the response to questions 2 and then reviewed the comments of those in the upper quartile of this rank and of those in lower quartile of this rank. The comments from those in this upper quartile included: "Novel experience to highlight real possibility \& remote theatre being experienced as close to live as possible."

"Really great idea, loved how seamlessly the characters transferred between on screen and real life. Amazing how it all worked out looking at the amount of tech. Great!"

"Exciting, innovative, captivating, unexpected. Marvelled at the skill of the direction \& acting as it was so slick despite the many technical elements. Atmospheric lighting. Great set. Adored the delightful puppets. Dazzled by the clever technical/visual tricks. All the different camera angles kept your attention, so that it was impossible to drift. I feel kids would hugely benefit from this facet of the experience. A lot going on, so hard to get bored!"

In the same vein, we looked at what the bottom $25 \%$, those who scored remote immersion below 36 , did not like; i.e. those for whom it did not work.

"Film less engaging - did not always join together smoothly \& therefore disrupted the narrative. Prospero's reading from the script detracted from the fantasy \& upset the eye contact between him \& the players."

"The engagement between characters off screen to on screen, very disjointed \& difficult for the actors to truly connect. Voice delay was a little distracting. Music \& sound from other venue very distant. Story lost its strength, difficult to engage with the performance as a whole. I sense that the experiment probably had more strength in the other venue. Good luck xxx"

"The sound quality - that prevented a sense of immersion more than any disparity between visuals. Get the sound quality up and it would be truly brilliant (but I'm sure you know that!!)"
Although we distilled the quotes above to illustrate the differences between high and low immersion participants, we also inspected all the like and dislike quotes; overall it is not easy to distinguish between them. Some comments are about the sense the distributed play made. We saw these comments in particular from those who also saw the (open air) stage version. Most of the 'likes' reflect how much they are fans of Miracle Theatre Company; there is a lot of good will whether people thought it was a success or not. Other comments are about the technology per se. This is partly to be expected as the audience were invited to an experiment with technology. The real success of applying this kind of technology, one might argue, would lie in an audience not noticing the technology. However, that is beyond the experimental nature of the trial.

\subsection{Expert Interviews}

The interviews and written feedback from members of the creative and technical teams have been analysed. A number of themes have emerged which form the frame for this section of the results. They include broad reflections on:

- the system supporting natural communication

- applications to future theatre practice

- stories suited to distributed performance

- the experience for the audience

\subsection{1 ..on supporting natural communication.}

The system worked well and provided a very clear communication channel which the creative team used without thinking. In this use case, objective measures of the system's performance do not tell the whole story. Obviously delays in the video transmission system had to be low enough that parties in each performance location could converse in a way that seemed natural to the audience and delay has an impact on the ability to communicate naturally but the $320 \mathrm{~ms}$ delay we measured does not tell us how natural the interactions were. Tests that attempt to provide objective measures of conversational analysis, looking for things like double starts and double talk are being developed for more controlled conditions [25], in this case we report observations of the actors, directors and crew as they used the system; and they seemed to use the system very naturally. This perception was shared by the Artistic Director who recalled that: "People started behaving as if they were in the same room very quickly, when you're in down time they all start fooling round telling jokes teasing each other that sort of thing absolutely as if they were in the same space".

\subsection{2 ...on application to future theatre practice}

One of the remarkable discoveries was that the communication system could be used in the daily working practice of the Miracle Theatre Company to support distributed working. The General Manager observed: "The thing I.. enjoyed most was seeing the working practice between the two spaces, the rehearsal, and the way people were interacting between the two spaces using the technology....we were using the technology in our real practice and I thought this was really working well...you know - if [the Artistic Director] was in New York we could use that for rehearsals for a week if you had to... and that would be quite exciting."

Similarly both one of the actors and the Artistic Director felt comfortable with the prospect of using the technology as a means for conducting remote rehearsals. The actor believed it could be suitable for "Theatrical groups that couldn't meet otherwise, whether you do a collaboration between countries, whether it is a 
telepresence rehearsal process" and the Artistic Director commented: "this set up, if you were to try and do a coproduction with a theatre company in another country or at the other end of this country, where it wouldn't be financially viable or practical to work together you could actually work using this technology really easily. People started behaving as if they were in the same room, very quickly".

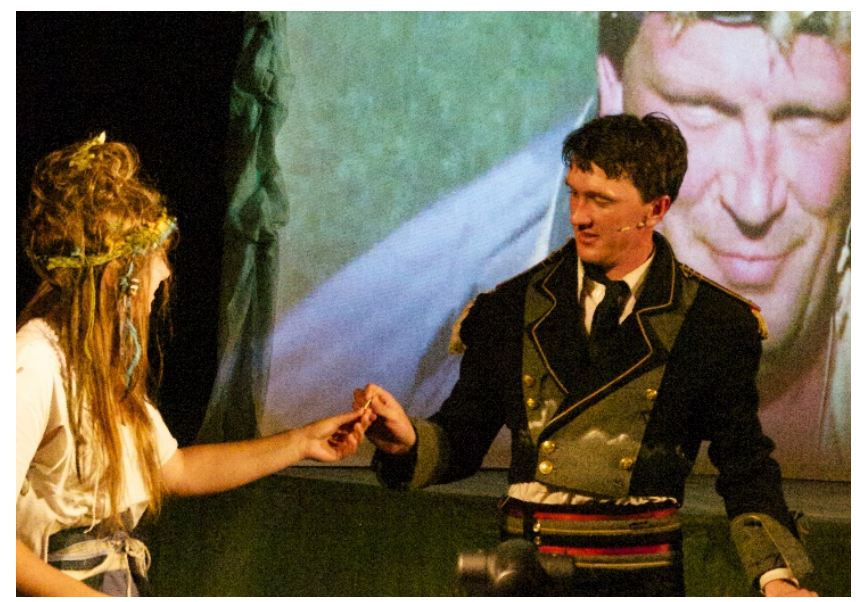

Figure 6 Left to Right: Hannah Stevens (as Miranda) and Ciaran Clarke (as Prince Ferdinand) and Angus Brown (as Prospero), showing how close-up of Prospero helps convey a God-like omnipotence.

\section{3 .3 ... on stories suited to distributed performance}

There were limitation with the approach taken here. Specifically we tried to impose upon a well-established single stage production the artifice of two performance spaces. Some virtue could be found in this and some compelling shot choices could deliver a "mesmerising effects" but on reflection the creative team knew that, were they to attempt another distributed production, then that production should, from the beginning, integrate the technology into the production. At times, the creative team struggled with the technology as there was a tension between technology push from the project team and the lack of predetermined requirements from an artistic perspective. The push was for a deterministic representation of an imagines performance.

Our scripting tools started with a user interface based on a timeline representation that looked like a non-linear editing tool. This was extended with elements such as abstract shot types and screen layout templates. During the course of the production it became clear that the creative team needed additional technology elements such as preview and pre-visualisation which would support a much more iterative approach. It also became clear that the tools and the associated scripting language were an integral part of the creative artefact. We regard this as analogous to the way in which non-linear editing suites, and the language they use, define many aspects of film and television. Our use of new tools, technology and language to define and create video-mediated distributed theatre suggests a new genre of media; one that cannot be supported entirely using concepts and approaches from existing genres. The tension between technology and creativity was allowing this technologically-enabled genre to emerge. And it raises the question: is this a new genre?

Our work was at its most rewarding when the creative team, of their own accord, validated the idea of the emergence of a genre, by speculating about specific productions which could be supported by the emerging toolset. The Artistic Director speculated on the stories that could be told:
"I have been thinking about it. I have got quite a specific thing really, I thought it would be nice to do an end of World War One project with a German theatre company and to use the technology for rehearsals but also for each to use the technology in their own way as part of the production"

We believe this is one of the most exciting developments to emerge from the production. This will be explored in more detail in a separate publication.

\section{3 .4 ...the experience for the audience}

This production did not seek to 'faithfully' and tediously broadcast from the theatre" [26] but to use screen language learned from TV and film to tell the story differently, as never told before and possibly, better. Whilst we struggled for time and the Artistic Director was aware of some shot choices that did not work as well as he would have liked, some shots worked really well.

The Artistic Director anticipated that the best audience experience would be in the Maritime Museum where there were 5 actors and 3 cameras. He anticipated that the experience in Dogbite studio, where Prospero was located, would be a lesser experience. He commented "I always thought that the main TV experience, you know where the five actors were... I always thought that would be a much more interesting audience experience but I am not sure it was in the end, they were both interesting...when the camera script was working well (the performance in the smaller venue) was really watchable, you were getting close into the action and you have a real live Prospero and a structured intimate view of what is happening in the other".

\section{CONCLUSION}

We have described an experiment in which we have used a novel communications technology platform to support a distributed performance of The Tempest. The scientific motivation was to test, in a highly situated and ecologically valid way, the postulation from the Vconect project that changing the way audio and video were captured transmitted and presented could positively affect group communication. The artistic challenge was to use the technology to emphasise some the nature of the characters and to explore how low cost technologies would be appropriated by a regional touring company in pursuit of their aims. There were two main technical objectives; the first was to establish whether it was possible to stream live theatre over consumer grade fast broadband connections; the second was to explore the capabilities of a system based on controllable cameras that semi-automatically develop simultaneous live streams, based on a scripted set of camera selections, for three different audiences (two theatres and the Internet audience).

The work focused on developing a performance for a paying audience and used audience feedback questionnaires, and in depth interviews with key practitioners to learn from the event. The audience feedback whilst overwhelmingly positive highlighted that the audience was likely to comment more favourably about aspects of the performance that related to their location, giving lower marks for the remote aspects of the performance. The audience response to the overall event was very positive.

Key observations emerging from the in depth interviews supported the Vconect project's postulation and suggested that the communication system would make a very effective tool for remote rehearsals; it also highlighted the need to develop, from scratch, stories that needed to be performed or rehearsed from split locations. 
The difficulties the creative team had in developing the production were largely addressed through a set of tools and an approach that were developed during the process. The fact that the difficulty existed at all, and that the tools and language used in existing genres of media were not sufficient to address the difficulties, suggests that distributed theatre may well need its own toolsets and its own language to thrive. The same was true for the pioneering days of film and television. This hints at a rather bold observation: that distributed theatre can be considered and treated as a new genre.

This new genre, supported by the technology we created, can be really attractive; according to the Artistic Director, it was able to create compelling new forms of theatre ...(in parts it was) really mesmerising; you were completely drawn into it and the image was telling you stuff and it was playing a part in your experience".

\section{REFERENCES}

1. Jacobs, J. 2000 "The Intimate Screen. Early British Television Drama." Oxford University Press.

2. Bakshi, H and Whitby A. 2014 "Estimating the Impact of Live Simulcast on Theatre Attendance: An Application to London's National Theatre." NESTA, 2014. Working Paper No. $14 / 04$.

3. Sheppard, R.M., Kamali, M., Rivas, R., Tamai, M., Yang, A., Wu, W., Nahrstedt, K. 2008 “Advancing interactive collaborative mediums through tele-immersive dance (TED): a symbiotic creativity and design environment for art and computer science." Proceedings of the 16th ACM international conference on Multimedia, 579-588.

4. Broadband Commission, The State of Broadband 2014: Broadband for all. broadbandcommission.org.

5. Stevens, T., Kegel, I., Williams, D., Cesar, P., Kaiser, R., Farber, N., Torres, P., Stenton, P., Ursu, M., and Falekalis, M. "Video communication for networked communities: Challenges and opportunities." 2012. Proceedings 16th International Conference on Intelligence in Next Generation Networks.

6. Ursu, M.F., Stollenmayer, P., Williams, D., Torres, P., Cesar, P., Farber, N., and Geelhoed, E. "Smart Video Communications for Social Groups - The Vconect Project." Integrating Social Media with Video Communications (ed Kaiser R.,) IEEE Computer Society Special Technical Community on Social Networking E-LetteR. June 2014, Vol. 2,2 .

7. Causey, M. 1999 "The Screen Test of the Double: The Uncanny Performer in the Space of Technology." Theatre Journal, Vols. 51, 4, pp. 383-394.

8. Birringer, J. 2008 “Thinking Images: Paul Kaiser and Marc Downie in conversation with Johannes Birringer." Performance, Technology \& Science. (30) 2.

9. Dixon, S. 2007. "Digital Performance, a history of new media in theatre, dance, performance art, and installation." Cambridge MA : MIT,

10. Stinehelfer, B., Lugo, A.C., Martinson, Z., and Schneider, N. 2011. "Skype Duet." [dir.] Nikolaus Schneider. [perf.] Brina Stinehelfer. New York \& Berlin. Per Aspera Productions,

11. Dimanche Rouge. Dimanche Rouge. [Online] [Cited: 14 July 2015.] www.dimancherouge.org.
12. Quacquarelli, A.J., Paciotto, A., and Yoo, M. 2011. "Discovering Pasolini." [dir.] A Garbagnati. La MaMa,

13. Ricke, J. and Lee, L. 2014. "Graphic Ships.” [prod.] Jesse Ricke. 3rd Networked Music Festival, Birmingham : CultureHub Inc, 26-28 September

14. Lee, T. 2014. "The Return." New York, La Mama, Culture Hub, https://www.youtube.com/watch?v=YJy3ME9bc5I.

15. Cremona, C. 2011 "Skype and videoperformance: relational screens." Proceedings of the International Symposium on Electronic Art.

16. Kegel, I., Cesar, P., Jansen, J., Bulterman, D.C.A., Kort, J., Stevens, T. and Farber, N. Enabling 'Togetherness' in HighQuality Domestic Video Conferencing. 2012. Proceedings of the 20th ACM international conference on Multimedia 159168.

17. Chen, S.,Gao, Z., Nahrstedt, K., and Gupta, I. 3DTI Amphitheater: Towards 3DTI Broadcasting. 2015. ACM TOMM, 11(2s): article 47.

18. National Theatre. 2010. "NT Live Digital broadcast of theatre. Learning from the pilot season." London : NESTA,

19. Latulipe, C., Carroll,E.A., and Lottridge, D. 2011 "Love, hate, arousal and engagement: exploring audience responses to performing arts." Proceedings of ACM CHI: 1845-1854.

20. Wang, C., E. Geelhoed, E., Stenton, P., and Cesar, P. 2014 "Sensing a Live Audience." Proceedings ACM CHI: 19091912.

21. Tseng, Y.C., Huang, Y.C., Wu, K.Y., Chin, C.P. 2012. "Dinner of Luciérnaga: an interactive play with iPhone app in theater." Proceedings of ACM Multimedia: 559-568.

22. Cerratto-Pargman, T., C. Rossitto, C., Barkhuus, L. 2014 "Understanding audience participation in an interactive theater performance." Proceedings of the Nordic Conference on Human-Computer Interaction: 608-617.

23. Bulterman, D.C.A. et al. 2008. "Synchronized Multimedia Integration Language (SMIL 3.0).” W3C. [Online] 2008. http:// www.w3.org/TR/SMIL/.

24. Ursu, M., Falekalis, M., Groen, M., Kaiser, R., and Frantzis, M.. 2015 "Experimental Enquiry into Automatically Orchestrated Live Video Communication". Proceedings of ACM International Conference for Television and Online Video pp63-72 (TVX 2015).

25. Schmitt, M., Gunkel, S., Cesar, P., and Hughes, P., "A QoE Testbed for Socially-Aware Video-Mediated Group Communication." International Workshop on SociallyAware Multimedia Workshop, ACM Multimedia 2013.

26. Gardner, C and Wyver, J. 1983 "From Reithian Reverence to Cost Accounting and Censorship." Screen 24:4-5, 1983, pp. 114-129. 